PERIODONTICS; BEHAVIOURAL SCIENCE

\section{Cynical hostility as a determinant of toothbrushing frequency and oral hygiene}

Mettovaara H-L, Suominen-Taipale A-L et al. J Clin Periodontol 2006; 33: 21-28

A lack of confidence may impede oral hygiene.

Cynical hostility is described as a lack of confidence in, or bitterness with, other people; subjects with this trait may be incapable of expressing adequate anger, and may have a poor lifestyle. In this study, questionnaires and oral health examinations were completed by 4,156 subjects out of a national Finnish sample of 8,028 .

A number of factors were correlated with greater frequency of tooth brushing and higher level of oral hygiene, including female gender, higher educational achievement, non-smoking, regular dental attendance, and a lower level of cynical hostility.

When the relationship of the highest level of cynical hostility to tooth brushing frequency was taken as unity, the cumulative OR for the lowest level of cynical hostility was 2.6 (CI 2.0-3.2), and in relation to the level of oral hygiene, it was 2.0 (1.6-2.4). The authors concluded that the trait was a marker of the frequency and quality of toothbrushing.

\section{doi:10.1038/sj.bdj.4813429}

\section{CARIOLOGY}

\section{Effect of caries experience in primary molars on cavity formation in the adjacent permanent first molar}

Leroy R, Bogaerts K et al. Caries Res 2005; 39: 342-349

Caries in deciduous molars predicted caries in the first permanent molar.

There is a well-known relationship between caries in the primary and secondary dentitions. The authors of this study consider the possibility that caries infection may pass from one tooth to another, but without accounting for the effects of diet on caries. A group of 4,468 children initially of mean age 7 yrs was examined annually on 6 occasions. Actual numbers varied from 3,239 to 4,351.

Proportions of sound first permanent molars (M1s) dropped to $76 \%$ in girls and 79\% in boys by the final examination. The risk of caries in M1s was greater when fissures had not been sealed, when there was more occlusal plaque, and when there had been caries in either of the adjacent deciduous molars, but particularly the second molar. The authors interpret this finding in relation to colonisation of M1s by pathogenic organisms.

However, there appeared to be no significant effect on M1 caries from restoration of deciduous cavities, a factor which points to the dominant role of dietary influences on caries in the individual.

\section{DENTAL TRAUMA}

\section{Avulsion of primary teeth and sequelae on the permanent successors}

Christopherson P, Freund M et al. Dent Traumatol 2005; 21:320-323

About $1 / 3$ of permanent successors suffered developmental disturbances.

There is little information on avulsion of primary teeth and subsequent effects on their successors. This study centred on a population of 4238 children born over an $18 \mathrm{yr}$ period and subsequently seen in 3 Danish dental clinics.

In this population, 35 children were identified (prevalence $0.8 \%$ ) with a total of 44 teeth which had been avulsed. Permanent successors which had not fully erupted by the end of the period were excluded from the study. Maxillary incisors were most frequently involved (39 cases).

By the end of the study, 33 successors had fully erupted and 10 had developmental disturbances: 5 had discolouration only, 3 had discolouration and hypoplasia, and 2, discolouration and horizontal enamel hypoplasia. There was a greater risk of developmental disturbances in children who were younger at the time of injury.

doi:10.1038/sj.bdj.4813431

PAEDIATRIC DENTISTRY; BEHAVIOURAL SCIENCE

Magic trick: a behavioural strategy for

the management of strong-willed children

Peretz B, Gluck G Int J Paediatr Dent 15: 429-436

Co-operation was quicker with a conjuring trick than with 'tell-show-do' (TSD) strategy.

Management of uncooperative dental behaviour is usually achieved by some procedure to allay anxiety, but it is important to avoid unintentional reinforcement of such behaviour. In this study, the widely-used TSD approach was compared with a "magic" trick (MT) in relation to the time taken for the child to sit in the dental chair, and acceptance of radiographic examination.

Children aged 3-6 yrs and identified as manifesting strongwilled behaviour were randomised to two groups of 35 for the two different approaches. Children in the MT group sat on the dental chair in a mean $141 \mathrm{~s}$, and those given TSD took a mean of $222 \mathrm{~s}(P=0.001)$, and 32 of the MT group accepted radiographs compared with 19 of the TSD group $(P=0.0013)$. Frankl's behaviour category was recorded for each child by the dentist, and 3 were rated negative in the MT group and 7 in the TSD group. Others were rated positive or very positive. The authors conclude that MTs may facilitate cooperative behaviour.

doi:10.1038/sj.bdj.4813432 